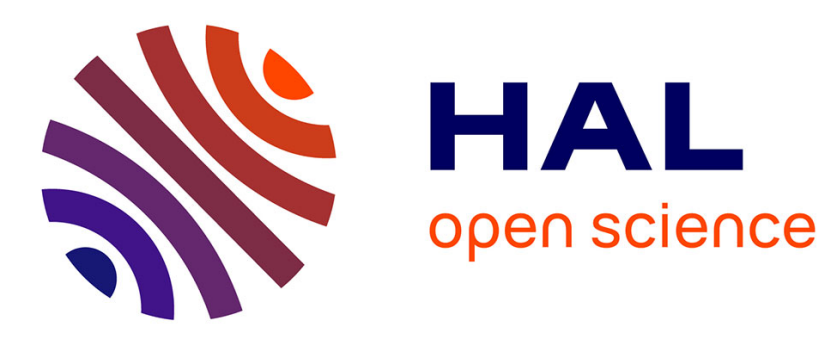

\title{
Effects of snout dimensions on the hydrodynamics of suction feeding in juvenile and adult seahorses
}

Gert Roos, Sam van Wassenbergh, Peter Aerts, Anthony Herrel, Dominique Adriaens

\section{- To cite this version:}

Gert Roos, Sam van Wassenbergh, Peter Aerts, Anthony Herrel, Dominique Adriaens. Effects of snout dimensions on the hydrodynamics of suction feeding in juvenile and adult seahorses. Journal of Theoretical Biology, 2010, 269 (1), pp.307. 10.1016/j.jtbi.2010.10.023 . hal-00653681

\section{HAL Id: hal-00653681 https://hal.science/hal-00653681}

Submitted on 20 Dec 2011

HAL is a multi-disciplinary open access archive for the deposit and dissemination of scientific research documents, whether they are published or not. The documents may come from teaching and research institutions in France or abroad, or from public or private research centers.
L'archive ouverte pluridisciplinaire HAL, est destinée au dépôt et à la diffusion de documents scientifiques de niveau recherche, publiés ou non, émanant des établissements d'enseignement et de recherche français ou étrangers, des laboratoires publics ou privés. 


\section{Author's Accepted Manuscript}

Effects of snout dimensions on the hydrodynamics of suction feeding in juvenile and adult seahorses

Gert Roos, Sam Van Wassenbergh, Peter Aerts, Anthony Herrel, Dominique Adriaens

$\begin{array}{ll}\text { PII: } & \text { S0022-5193(10)00557-6 } \\ \text { DOI: } & \text { doi:10.1016/j.jtbi.2010.10.023 } \\ \text { Reference: } & \text { YJTBI 6207 }\end{array}$

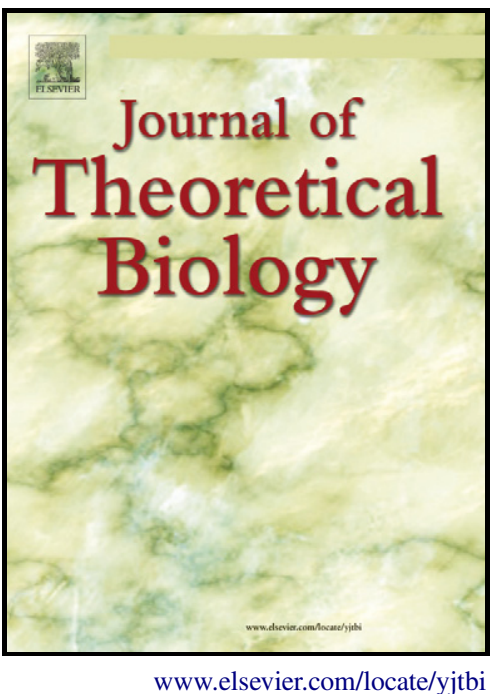

To appear in: $\quad$ Journal of Theoretical Biology

Received date: $\quad 19$ May 2010

Revised date: $\quad 18$ October 2010

Accepted date: $\quad 20$ October 2010

Cite this article as: Gert Roos, Sam Van Wassenbergh, Peter Aerts, Anthony Herrel and Dominique Adriaens, Effects of snout dimensions on the hydrodynamics of suction feeding in juvenile and adult seahorses, Journal of Theoretical Biology, doi:10.1016/j.jtbi.2010.10.023

This is a PDF file of an unedited manuscript that has been accepted for publication. As a service to our customers we are providing this early version of the manuscript. The manuscript will undergo copyediting, typesetting, and review of the resulting galley proof before it is published in its final citable form. Please note that during the production process errors may be discovered which could affect the content, and all legal disclaimers that apply to the journal pertain. 
1 Effects of snout dimensions on the hydrodynamics of suction feeding in juvenile and

2

3 5

6

7

8

9

Département d'Ecologie et de Gestion
Muséum National d'Histoire Naturelle

57 rue Cuvier, Case postale 55 75231, Paris Cedex 5

France

${ }^{\mathrm{d}}$ Evolutionary Morphology of Vertebrates Ghent University

K.L. Ledeganckstraat 35

B-9000 Gent

Belgium
Fax: 32-3820.22.71

Phone: $32-3820.22 .60$

E-mail: Gert.Roos@ua.ac.be 


\section{Summary}

2

3 Seahorses give birth to juveniles having a fully functional feeding apparatus, and juvenile

4 feeding behaviour shows striking similarities to that of adults. However, a significant

5 allometric growth of the snout is observed during which the snout shape changes from

6 relatively short and broad in juveniles to relatively long and slender in adults. Since the shape

7 of the buccal cavity is a critical determinant of suction performance, this snout allometry will

8 inevitably affect the suction feeding ability. To test whether the snout is optimised for suction

9 feeding throughout ontogeny, we simulated the expansion of different snout shapes varying

10 from extremely long and slender to short and broad for juvenile and adult snout sizes using

11 computational fluid dynamic models. Our results showed that the snout diameter at the start

12 of the simulations is involved in a trade-off between the realisable suction volume and

13 expansion time on the one hand (improving with larger initial diameters), and maximal flow

14 velocity on the other hand (improving with smaller initial diameters). Moreover, suction

15 performance (suction volume as well as maximal attainable flow velocity) increased with

16 decreasing snout length. However, an increase in snout length decreases the time to reach the

17 prey by cranial rotation, which may explain the prevalence of long snouts among syngnathid

18 fishes despite the reduced suction performance. Thus the design of the seahorse snout

19 revolves around a trade-off between the ability to generate high-volume suction versus

20 minimisation of the time needed to reach the prey by cranial rotation.

22 Keywords: Syngnathidae, feeding, expansion, ontogeny, CFD 


\section{1. Introduction}

2

3 Juveniles often show strong morphological differences in comparison to adults. During

4 ontogeny these differences may be reflected in positive or negative allometric growth in

5 certain morphological features $[1,2,3,4,5]$ or in the development of novel morphological

6 structures or linkages at a certain age $[6,7,8]$. These differences in morphology in turn often

7 result in differences in performance or behaviour during ontogeny as shown by a number of 8 previous studies $[9,10]$.

9 During early ontogeny, vertebrates often show a reduced feeding performance compared to their adult life stages [10]. For instance, bite force shows a positive allometry with respect to body and head dimensions in fish [11], lizards [4], turtles [12], crocodiles [13], 12 birds [14] and mammals [15]. Similar to bite force, the linear velocity of upper an lower jaw tips also increases with increasing body size, suggesting that larger animals are able to capture larger and more elusive prey $[2,4,10,16]$. Previous studies also suggested that suction feeding 15 performance, the most common prey capture strategy of aquatic vertebrates, increases with increasing body size $[17,18,19]$, which may explain why larger animals show a more diverse

17 diet than smaller conspecifics.

Whereas most suction feeders require a period of maturation involving a gradual improvement in their feeding performance after hatching, seahorses give birth to young with a fully functional feeding system specialized for pivot feeding, a special type of suction feeding [20,21]. Exceptionally high rotational velocities of the snout toward the prey (first phase of pivot feeding), followed by relatively large buccal expansions (second phase of pivot feeding) were observed in juvenile Hippocampus reidi compared to adults [22]. The high performance of newborn seahorses can be explained by the fact that male seahorses provide post-zygotic 
1 developmental stage involving a greater degree of maturation of the feeding system [20,23].

2 Despite the similar prey capture behaviour, and at first sight high performance in both

3 newborn and adult seahorses, considerable allometric growth of head and snout dimensions

4 occurs during ontogeny in seahorses [22,24]. Newborn juveniles bear a relative short and

5 broad snout, which becomes significantly longer and more slender as they grow. A recent

6 study showed that both juveniles and adults show a snout length that is approximately optimal

7 to reach the prey as fast as possible by rotating the head for a given width of the snout [22].

8 Therefore, the allometry in snout length could be a functional response to the differences in

9 snout width between juveniles and adults. However, since the study by Roos et al. [22] only

10 focused on the optimization of snout length (and not width or height) for performance during

11 the first phase of pivot feeding (i.e. head rotation), this means that it remains currently

12 unknown whether the observed allometry in snout dimensions in seahorses is driven by

13 functional demands.

14 Indeed, the allometric increase of head and snout dimensions may have important 15 consequences for the second phase of pivot feeding: the generation of suction by buccal 16 expansion. During buccal expansion, a negative pressure is generated inside the buccal cavity, 17 which causes the water in front of the predator to flow towards and into the predator's mouth 18 [25]. When the suction force overcomes the prey's inertia and escape response, the prey with 19 the surrounding water are drawn into the suction feeder's mouth $[18,26]$. A study by Van 20 Wassenbergh et al. [18] showed that the shape of the buccal cavity at rest has a very important 21 effect on suction performance. Since also the absolute size of the buccal cavity strongly 22 influences the flow patterns and energetics of buccal expansion [27], the shape change in the 23 buccal cavity during ontogeny of Hippocampus reidi may be a response to the hydrodynamics 24 of suction feeding. 
This paper aims to address the question whether snout allometry in seahorses can be

2 explained as a response to hydrodynamic constraints. In this context, two alternative scenarios

3 could explain the snout allometry in H. reidi: (1) the juveniles expelled from the male's brood

4 pouch have a snout that is suboptimal for suction feeding due to developmental or other

5 constraints. Therefore, the snout proportions change rapidly to bypass the suboptimal stage as

6 quickly as possible. (2) The snout dimensions in newborn juveniles are already optimized for

7 suction feeding. The snout allometry is dictated by the changing hydrodynamic constraints

8 during growth (for example the gradually less viscous flow regime). We will test these

9 hypotheses by hydrodynamic modelling of snout expansion in juvenile and adult

10 Hippocampus reidi.

12 2. Material and methods

\subsection{Mesh construction}

15 In analogy with Van Wassenbergh and Aerts [28], a 2D axisymmetric, unstructured triangular mesh was created using GAMBIT 2.3.16 (Ansys, Lebanon, NH, USA). In this mesh, the

17 snout was modelled as a cylinder (open at the mouth side and closed at the opercular side)

(Fig. 1A, B). A cone was attached to this cylinder to avoid abrupt changes in the flow pattern

(Fig. 1B). A cylindrical open boundary surface enclosed the flow domain. The distances of the nodes were smaller near the snout $(0.006 \mathrm{~mm}$ and $0.10 \mathrm{~mm}$, for juveniles and adults, 21 respectively) than those at the boundary of the domain $(0.08 \mathrm{~mm}$ and $1 \mathrm{~mm}$, for juveniles ad adults, respectively) to increase the accuracy of the results of the simulations.

Previous studies used more complex cylinder or cone geometries to calculate flow

24 velocities and pressures inside the buccal cavity using hydrodynamically simplified analytical 25 models [18,27,29,30]. They argued that a single expanding cylinder should better be divided 
1 into a series of smaller cylinders or cones which expand at different timings to mimic the

2 typical anterior to posterior expansion sequence of the buccal cavity more accurately. Since

3 the expansion of the snout in the seahorse Hippocampus reidi resembles a radially expanding

4 cylinder, and the prey is always engulfed long before the more posterior elements (e.g.

5 opercula) start to expand [29], we chose this simple, cylindrical expansion as a model system.

7 preserved in neutralised and buffered formalin solution were photographed digitally. The

8 snout length, height and width of each individual were measured in each photograph using the

9 ImageJ software (1.41m, W. Rasband, National Institute of Mental Health, Bethesda, MA,

10 USA). The distance between the snout tip and the anterior part of the frontal bone (anterior to

11 the eye) was defined as the snout length (Fig. 1A). Snout height was measured as the distance

12 between the articulation of the lower jaw with the quadrate and the anterior tip of the vomer

13 (Fig. 1A). The distance between the left and right articulation of the lower jaw with the

14 quadrate was defined as the snout width (Fig. 1A). The mean snout length was taken for the

15 juvenile and adult age class to represent the length of the model. To create an axially

16 symmetric model, the square root of the product of the average snout width and the average

17 snout height was taken to obtain the radius of the model (Fig. 1B). In this way cross-sectional

18 areas and volume remain unaffected [28].

\subsection{Mesh motion}

21 The computational fluid dynamics (CFD) simulation of the expansion of the model was 22 performed in FLUENT 6.3.16 (Ansys, Lebanon, NH, USA). To simulate the axial abduction 23 of the snout, FLUENT-user defined functions (DEFINE-CG-MOTION UDFs) were utilised.

24 The maximal expansion and the expansion time of the juvenile and adult model were based 25 on data derived from previous studies [20,29]. All UDFs were compiled using Microsoft 
1 Visual Studio 2005. Radial movement of the entire snout was simulated using a sine function

2 in which the expansion velocity increases to a maximum halfway the expansion (Fig. 1C).

3 Because expansion is the same at each point along the axis of the cylinder, the initial diameter

4 of the cylinder at the open side is also the initial mouth diameter. Note that, there is no

5 forward movement of the model during the simulations, which is also found in seahorse

6 feeding [22].

$7 \quad$ Numerical algorithms were used to update the mesh relative to the input motion in 8 each time step using two methods. The first method was a spring-based smoothing method.

9 Here, the edges connecting the nodes were considered as springs with a spring factor of 1.0 and a boundary node relaxation factor of 1.0 , and a convergence tolerance of 0.001 [28]. In

11 the second method, cells which became critically small $\left(<1 \times 10^{-6} \mathrm{~mm}\right.$ and $<5 \times 10^{-6} \mathrm{~mm}$ for

12 the juvenile and adult model, respectively) or large $\left(>5 \times 10^{-5} \mathrm{~mm}\right.$ and $\left.>5 \times 10^{-5} \mathrm{~mm}\right)$ or too 13 skewed $(>0.6$, with skewness defined as the difference in triangle shape between an 14 equilateral triangle and a triangle with equivalent volume) during mesh motion were 15 remeshed by FLUENT.

$17 \quad 2.3$ CFD settings

18 In FLUENT 6.3.16, unsteady flow simulations were performed in which laminar flow was 19 assumed [28]. The no-slip wall condition was enforced at the moving surfaces of the snout, 20 which is the default condition for models of viscous flow in FLUENT 6.3. The cylindrical 21 open boundary surface of the domain (Fig. 1C) was modelled as a pressure-outlet where a 22 gauge pressure of zero applies (i.e. no changes in pressure due to the fish is assumed at this 23 boundary) and a backflow normal to the boundary.

24 The pressure-based solver (chosen to obtain fast-converging solutions) was used with 25 a node-based Green-Gauss gradient treatment. The latter achieves higher accuracy in 
1 unstructured triangular grids compared to the cell-based gradient treatment. The first-order

2 implicit unsteady formulation option was used in the simulation because moving mesh

3 simulations currently only work with first-order time advancement. The standard pressure

4 discretization scheme was used for the pressure calculation and a second-order upwind

5 scheme was used for momentum equations. The pressure-velocity coupling was solved using

6 the SIMPLE scheme. The latter is a discretization method that uses a relationship between

7 velocity and pressure corrections to enforce mass conservation and to obtain the pressure

8 field. A constant amount of 125 time steps were used, consequently the time step size was

$9 \quad 0.00004 \mathrm{~s}$ and $0.00016 \mathrm{~s}$ for the juvenile and adult simulation, respectively. A maximum of 50

10 iterations per time step was sufficient to reach convergence.

\subsection{Calculation of power requirement}

13 The total power required from the feeding system to realize the buccal expansion that was

14 prescribed was calculated by taking the product of the radial component of the pressure forces

15 and radial velocities of each of the two faces (i.e. external and internal mesh surface

16 subdivisions) of the modelled buccal cavity, and by summing these powers for the entire

17 buccal surface. This calculation was automatically performed after each time step by

18 including a DEFINE_EXECUTE_AT_END user-defined function in the program [28].

19 Recent studies showed that the work input of the epaxial and hypaxial musculature

20 provide the largest fraction of total suction power in fish $[31,32,33,34]$. In pivot feeders, the

21 kinetic energy delivered by the epaxial muscles is primarily driven by elastic recoil of the

22 epaxial muscles and tendons [34,35]. When maximal head rotation is reached, the kinetic

23 energy is either dampened by cranial structures or (partially) transferred and used to expand

24 the snout. For the purpose of the simulations, we assume that the energy needed to expand the

25 buccal cavity has the same order of magnitude as the kinetic energy needed to rotate the head. 
The maximum calculated work input (integral of instantaneous power over time) of

2 each age class was compared to the power requirement to rotate the head in each age class to

3 evaluate whether the magnitude of the calculated power requirement was realistic. First, the

4 kinetic energy of head rotation was calculated as the product of the head's moment of inertia

5 and the head's angular velocity squared divided by two [22]. This kinetic energy was

6 multiplied by 1.5 to account for the added mass [22,34]. Next, we assumed that the hypaxial

7 muscles can provide an additional $10 \%$ to the kinetic energy of the epaxial muscles, since the

8 mass of the hypaxial muscles is ten times less than that of the epaxial muscles (G. Roos, 9 unpublished data).

\subsection{Simulation of different snout shapes}

12 The average measured snout radius and snout length of the juveniles and adults were 13 multiplied by $0.5,0.75,1,1.5$ and 2 to obtain 25 different snout morphologies for each age 14 class ranging from long and slender snouts to short and broad snouts. Two sets of simulations 15 were performed for each juvenile and adult snout morphology. In the first set of simulations, we assumed that potential changes in the muscle-tendon physiology and the gearing 17 properties of force and velocity within the buccal expansion system are highly constrained, so that suction power can only be generated within a fixed time interval. In these simulations, the

19 expansion volume was adjusted to meet our general assumption that the amount of work input 20 from the musculature remains equal. In the second set of simulations, we assumed that 21 changes to the morphology of the cranial elements of the expansion system are highly 22 constrained, so that only a fixed, maximal expansion volume can be realized. In these 23 simulations, the expansion duration was varied to meet our general assumption that the 24 amount of work input from the musculature remains equal. Consequently, depending on 25 which type of morphological, behavioural or physiological changes are most likely to occur 
1 by means of evolution or via phenotypical plasticity, one would either expect the first set of

2 simulations (in case of a variable cranial expansion magnitude) or the second set of

3 simulations (in case of a variable duration of suction power generation) to be more relevant.

4 Note, however, that probably a combination of both types of modifications would occur in

5 nature, but we must separate these two effects (expansion duration and expansion magnitude)

6 for our model to become determined.

7 As mentioned above, in the first set of simulations we assumed that the expansion time

8 remains constant. Per snout morphology, we ran up to five simulations with different

9 maximum snout expansions, which resulted in different work inputs. Linear interpolations

10 were performed to obtain the maximal volume change that a particular snout morphology can

11 generate with a constant amount of expansion time and work. In the second set of simulations,

12 we assumed that the volume change realised by expansion remains constant (equal amount of

13 water sucked into the snout). Again, up to five simulations were run to obtain a set of

14 different expansion times with different work inputs. Interpolations enabled us to pinpoint the

15 minimal expansion time needed to expand up to a constant volume change the given, realistic

16 estimate of constant work input. In turn, this result was used to obtain the maximal flow

17 velocity at the gape and the minimal pressure inside the buccal cavity.

18 In addition, the growth trajectory of the snout shape ranging from early juvenile to

19 adult was superimposed on the adult hydrodynamic simulation results to investigate the

20 implications of ontogenetic snout shape changes on the characteristics of suction. This

21 trajectory is based on measurements of the snout dimensions (length, height and width) of

22 seahorse specimens of different ages ranging from 1 day old to 20 weeks old (adult). To

23 eliminate absolute size differences, the snout dimensions in this ontogenetic series were

24 scaled up to the buccal volume of the adult snout. 


\section{3. Results}

2

33.1 Hydrodynamic effects of differences in length and initial diameter for a given expansion

4 time and work input

5 In the following simulations, the radial expansion magnitude was adjusted for each cylindrical

6 CFD model with a different starting geometry (i.e. length and initial diameter) such that the

7 expansion always required the same work input $\left(0.610^{-9} \mathrm{~J}\right.$ and $610^{-3} \mathrm{~J}$ for juveniles and

8 adults, respectively) from the animal's feeding musculature. The time needed to perform the

9 expansion (5 ms for juveniles and $20 \mathrm{~ms}$ for adults) was not adjusted.

\subsubsection{Juveniles}

Our CFD simulations showed that suction generated by radial expansion of a cylinder that is relatively broader and shorter than the cylinder modelled based on the dimensions of the snout of a juvenile seahorse allowed a larger volume increase for a given work input (Fig. 2A). For instance, the average measured juvenile snout has a length of $0.7 \mathrm{~mm}$ and an initial diameter of $0.32 \mathrm{~mm}$ and expanded by $0.08 \mathrm{~mm}^{3}$ during suction feeding. A relatively broader and shorter snout with a length of $0.35 \mathrm{~mm}$ and an initial diameter of $0.64 \mathrm{~mm}$ can be expanded by $0.2 \mathrm{~mm}^{3}$ for the same work input, which is approximately 3 times higher (Fig. 2A). In contrast, a relatively long and slender cylinder with a length of $1.4 \mathrm{~mm}$ and an initial diameter of $0.16 \mathrm{~mm}$ could only expand by $0.01 \mathrm{~mm}^{3}$, which is 8 times less compared to the original model of the juvenile seahorse (Fig. 2A).

The maximal flow velocity calculated at the gape, increased when the starting geometry of the cylinder was made shorter and more slender (Fig. 2C). The maximal flow

24 velocity of the expanding cylinder modelled after the juvenile snout was $0.2 \mathrm{~ms}^{-1}$. Starting the 25 expansion from a more slender and shorter cylinder (length $=0.35 \mathrm{~mm}$, initial diameter $=0.16$ 
$1 \mathrm{~mm}$ ), increased the maximal flow velocity by 2 times to $0.3 \mathrm{~ms}^{-1}$ (Fig. 2C). In contrast, a

2 relatively longer and broader snout (length $=1.4 \mathrm{~mm}$ and initial diameter $=0.64 \mathrm{~mm}$ )

3 generated a maximal flow velocity of $0.07 \mathrm{~ms}^{-1}$, which is 3 times less than the peak velocity

4 output for the original model (Fig. 2C).

5 The maximal sub-ambient pressure difference at the expanding cylinder surface

6 increases predominantly as a function of decreasing initial diameter (Fig. 2E). For the model

7 of the average juvenile snout, the maximal sub-ambient pressure difference was $69 \mathrm{~Pa}$. This

8 pressure difference is 2 times higher compared to the sub-ambient pressure difference of 41

9 Pa induced by an expanding cylinder with the same length $(0.70 \mathrm{~mm})$, but with an initial diameter of $0.64 \mathrm{~mm}$ (Fig. 2E). If the cylinders length was kept at $0.7 \mathrm{~mm}$ and the initial

11 diameter reduced to $0.16 \mathrm{~mm}$, a sub-ambient pressure difference of $228 \mathrm{~Pa}$ was generated

12 during suction, which is 3 times higher than the value calculated for the original juvenile 13 seahorse model (Fig. 2E).

\subsubsection{Adults}

For models of adult seahorse snouts, the maximum attainable volume for a given expansion

17 time and work input from the musculature increases with a relatively shorter and broader initial geometry (Fig. 2B). The model of the average adult snout (length $=11 \mathrm{~mm}$, initial diameter $=2.28 \mathrm{~mm}$ ) was able to increase by $157 \mathrm{~mm}^{3}$ during suction, which is 4 times higher than the $41 \mathrm{~mm}^{3}$ expansion achieved by a snout with a length of $22 \mathrm{~mm}$ and a diameter of

$211.14 \mathrm{~mm}$ (Fig. 2B). On the other hand, a snout with a length of $5.5 \mathrm{~mm}$ and an initial diameter of $4.56 \mathrm{~mm}$ could expand by $427 \mathrm{~mm}^{3}$ for the same work input, which is 3 times higher than our original adult Hippocampus reidi model (Fig. 2B).

The maximum flow velocity increases mainly with decreasing initial snout diameter

25 (Fig. 2D). The highest flow velocity of $1.6 \mathrm{~ms}^{-1}$ is found for a cylinder with a length of $11 \mathrm{~mm}$ 
1 and an initial diameter $1.14 \mathrm{~mm}$, which is slightly higher than the maximal flow velocity of

$21.2 \mathrm{~ms}^{-1}$ generated by the model of the average adult snout (length $=11 \mathrm{~mm}$, initial diameter $=$

$32.28 \mathrm{~mm}$ ) (Fig. 2D). When this $11 \mathrm{~mm}$ long cylinder becomes broader (initial diameter $=4.56$

$4 \mathrm{~mm}$ ), the maximal flow velocity decreases to $0.9 \mathrm{~ms}^{-1}$, which is 2 times lower than the flow

5 velocity attained by the original adult Hippocampus reidi snout model (Fig. 2D).

7 increase with increasing snout length and decreasing initial diameter (Fig. 2F). The maximal

8 sub-ambient pressure difference of the model of the adult Hippocampus reidi snout is $2.1 \mathrm{kPa}$,

9 which is 3 times higher than the maximal sub-ambient pressure difference of $0.8 \mathrm{kPa}$ created

10 by a cylinder with length $5.5 \mathrm{~mm}$ and initial diameter $4.56 \mathrm{~mm}$ (Fig. 2F). In contrast, the

11 maximal sub-ambient pressure difference calculated for a cylinder with a length of $22 \mathrm{~mm}$

12 and an initial diameter of $1.14 \mathrm{~mm}$ is $4.8 \mathrm{kPa}$, which is 2 times higher than the value

13 calculated for the original model (Fig. 2F).

14

15 3.2 Hydrodynamic effects of differences in length and initial diameter for a given volume 16 increase and work input

17 In the following simulations, the time needed to perform a radial expansion of fixed 18 magnitude $\left(0.08 \mathrm{~mm}^{3}\right.$ for juveniles and $157 \mathrm{~mm}^{3}$ for adults) was adjusted for each cylindrical 19 CFD model with a different starting geometry (i.e. length and initial diameter) such that the

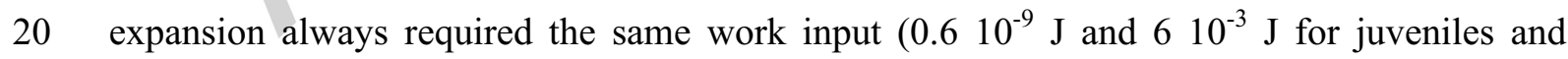
21 adults, respectively) from the animal's feeding musculature.

3.2.1 Juveniles

24 Suction generated by radial expansion of a relatively longer and more slender cylinder than 25 the one modelled after the snout of a juvenile seahorse caused the expansion time to increase 
1 (Fig. 3A). The expansion time for the model of the average measured juvenile Hippocampus

2 reidi snout with a length of $0.7 \mathrm{~mm}$ and an initial diameter of $0.32 \mathrm{~mm}$ was $5 \mathrm{~ms}$. For a long

3 and narrow cylinder (length $=22 \mathrm{~mm}$, initial diameter $=0.16 \mathrm{~mm}$ ), the shortest realizable

4 expansion increases by 4 times to $19 \mathrm{~ms}$ compared to the original juvenile snout model (Fig.

5 3A). In contrast, for a broader and shorter cylinder (length $=0.35 \mathrm{~mm}$, initial diameter $=0.64$

$6 \mathrm{~mm})$, the shortest feasible expansion time decreased to $2 \mathrm{~ms}$, which is 4 times less compared

7 to the original juvenile seahorse model (Fig. 3A).

8 The maximum suction-induced flow velocity increases with decreasing cylinder length

9 and initial diameter (Fig. 3C). For example, the maximum flow velocity for the original

10 juvenile snout model $\left(0.2 \mathrm{~ms}^{-1}\right)$ was 1.5 times lower than the maximal velocity of $0.3 \mathrm{~ms}^{-1}$ for

11 a relatively narrow and short snout (length $=0.35 \mathrm{~mm}$, initial diameter $=0.16 \mathrm{~mm})($ Fig. $3 \mathrm{C})$.

12 When the expanding cylinder's length and initial diameter increased to $1.4 \mathrm{~mm}$ and $0.64 \mathrm{~mm}$,

13 respectively, the maximal velocity decreased to $0.06 \mathrm{~ms}^{-1}$, which is 3 times less than that of

14 the original juvenile seahorse model (Fig. 3C).

15 The maximum sub-ambient pressure difference appeared to be primarily a function of 16 the length of the expanding cylinder: with increasing cylinder length, the maximum sub17 ambient pressure difference decreased (Fig. 3E). The maximum sub-ambient pressure 18 difference of the original juvenile model was $69 \mathrm{~Pa}$. This pressure difference increased to 90 19 Pa for a snout with an equal initial diameter but with a snout length of $0.35 \mathrm{~mm}$ (Fig. 3E). On 20 the other hand, the maximum sub-ambient pressure difference decreases 2 times to $40 \mathrm{~Pa}$ for a 21 snout with an equal initial diameter but with a length of $1.4 \mathrm{~mm}$ (Fig. 3E).

3.2.2 Adults

24 Similar to the juvenile models, the shortest feasible expansion time in adult expanding 25 cylinder models increased with increasing cylinder length and decreasing initial diameter 
1 (Fig. 3B). The expansion time of the original model of the average measured adult snout was

$220 \mathrm{~ms}$, which is 3 times less than the shortest realizable expansion time of $70 \mathrm{~ms}$ for a

3 cylinder with length $22 \mathrm{~mm}$ and initial diameter $1.14 \mathrm{~mm}$ (Fig. 3B). When the cylinder's

4 starting geometry was made relatively broader and shorter (length $=5.5 \mathrm{~mm}$, initial diameter

$5=4.56 \mathrm{~mm}$ ), the shortest attainable expansion duration decreases 3 times to $7 \mathrm{~ms}$ (Fig. 3B).

7 diameter (Fig. 3D). The maximal flow velocity of the original adult snout model was $1.2 \mathrm{~ms}^{-1}$.

8 The highest maximal flow velocity of $1.5 \mathrm{~ms}^{-1}$ in our sample was found for a cylinder with a

9 length of $5.5 \mathrm{~mm}$ and an initial diameter $2.28 \mathrm{~mm}$, which is only slightly higher than the

10 original model (Fig. 3D). The lowest maximal flow velocity of $0.7 \mathrm{~ms}^{-1}$ was found for the

11 cylinder with a length of $22 \mathrm{~mm}$ and an initial diameter $4.56 \mathrm{~mm}$, which is 2 times lower than

12 the original adult snout model (Fig. 3D).

13 The maximum sub-ambient pressure difference appeared mainly a function of the

14 length of the cylinder, and showed an increase with decreasing snout length (Fig. 3F). The

15 maximum sub-ambient pressure difference for the original adult seahorse model (length $=11$

$16 \mathrm{~mm}$, diameter $=2.28 \mathrm{~mm}$ ) was $2 \mathrm{kPa}$, this pressure difference is 2 times higher than the $1 \mathrm{kPa}$

17 found for a cylinder with the same initial diameter and a length $22 \mathrm{~mm}$ (Fig. 3F). For a

18 cylinder with the same initial diameter and with a length of $5.50 \mathrm{~mm}$, the maximum sub-

19 ambient pressure difference was $3 \mathrm{kPa}$, which is 1.5 times higher than that found for the 20 original model (Fig. 3F).

\subsubsection{Ontogeny}

23 As juveniles grow, the snout becomes relatively longer and more slender [22]. When 24 expansion time and amount of work input are considered constant, this shape change of the 25 snout theoretically results in lower maximal expansion volumes (Fig. 2B), but higher maximal 
1 flow velocities at the mouth (Fig. 2D). The maximal pressure inside the buccal cavity also

2 increases gradually as the snout becomes more slender (Fig. 2F). If the expansion volume and

3 work input are assumed constant, the expansion time increases as the juvenile grows (Fig.

4 3B). As a result, the maximal flow velocity at the mouth and the maximal pressure inside the

5 buccal cavity decrease (Fig. 3D, F).

\section{4. Discussion}

8

9 In this study, we focussed on the question of why snout allometry is observed during ontogeny in seahorses [22]. Undoubtedly, initial snout dimensions affect suction feeding

11 performance [18]. Therefore, we hypothesised that the observed snout allometry may be

12 related to the optimisation of suction feeding performance. To test this hypothesis, expansions

13 of the snout with a morphology as measured in juveniles and adults, as well as variations of

14 these snout shapes were simulated using computational fluid dynamic models (CFD). The

15 results of these simulations show that initial snout diameter cannot be considered optimized

16 for suction performance in general because it is confronted with a trade-off situation between

17 different aspects of suction performance (Fig. 2, 3). A decrease in the initial snout diameter

18 results in an increase in maximal flow velocity at the gape (Fig. 2C, D and 3C, D), but this

19 has the negative effects of 1) decreasing the amount of water drawn into the mouth by suction

20 (Fig. 2A, B) and 2) increasing the duration of a given expansion for a fixed work input (Fig.

$213 \mathrm{~A}, \mathrm{~B})$. Consequently, it is clear that morphology of the suction feeding apparatus represents

22 a complex trade-off between the different aspects of suction hydrodynamics investigated in 23 this study.

24 Suction performance was evaluated based on four hydrodynamic aspects of suction 25 feeding: volume increase, expansion time, flow velocity and intra-oral pressure. First, the 
1 ability to generate a larger volume increase is preferable, because more water can be moved in

2 the direction of the predator's mouth. Therefore, the feeding strike can be initiated when the

3 prey is further away from the mouth and larger prey can be captured [18,36]. Secondly,

4 minimizing the expansion time can be crucial because the prey then has less time to react and

5 escape the flow generated by the predator. Thirdly, realisation of higher flow velocities

6 positively influences suction performance, because prey dragged along with this flow will be

7 transported quicker towards and through the buccal cavity [20,26,37]. Finally, since, a

8 previous study showed that large intra-oral pressure drops during suction feeding can

9 considerably stress the skull [38], lower sub-ambient pressure magnitudes inside the buccal

10 cavity seem favourable. If the seahorse generates higher sub-ambient pressure magnitudes

11 inside the buccal cavity it must ensure that the morphology of the snout can cope with these

12 large pressure drops, for example by enforcing the structure of the snout. In turn, these suction

13 feeding characteristics might behave differently in environments with low and high Reynolds

14 numbers. Therefore, we simulated expansion of the different snout shapes at the juvenile scale

15 as well as the adult scale to account for these possible differences.

16 Seahorses typically capture small crustaceans suspended in the water column in such a

17 short time that the prey has no time to react. In that case, the approximately neutrally buoyant

18 prey are sucked along with the surrounding water, and the water flow velocity in the vicinity

19 of the prey also describes the velocity of the prey. However, in case prey are attached to the

20 substrate or display an escape response, suction performance can better be quantified by the

21 force excerted on these prey [20,26,37]. Recent studies showed that this force is almost

22 entirely caused by the pressure gradient in the water near the position of the prey [26]. To

23 complete our quantification of suction performance in our simulations, we also added graphs

24 showing the effect of initial snout dimensions on the pressure gradient (Fig. 4). The latter is

25 calculated in the mouth opening at the time of peak pressure. Note that, in general, a similar 
1 trend for pressure gradient is observed compared to peak flow velocity (Fig. 4 versus Fig. 2 2C,D and Fig. 3C,D).

3 As mentioned earlier, in all our simulations we assumed that the work input by the

4 feeding muscles limits suction performance. Given the elastic energy storage and release

5 mechanism used to power suction feeding in syngnathid fish [34], work input is the most

6 probable limiting factor in this case. A direct consequence of using a constant work input in

7 our simulations, is that sucking a larger parcel of water will inevitably go along with a drop in

8 peak suction flow velocity in our simulations. To asses this classical "suction volume versus

9 flow velocity trade-off' [30,36] more quantitatively, additional simulations were performed in

10 which the expansion volume of the measured adult and juvenile snout was altered $(0.5,0.75$,

$11 \quad 1.5$ and 2 times the original expansion volume) and the expansion time was adjusted to

12 equalize the amount of work input. From these simulations, the maximum flow velocity near

13 the mouth was extracted and divided by the original maximum flow velocity (when the ratio

14 of the expansion volume is 1). In adults, the relation between the relative flow velocity $(U)$

15 and the relative expansion volume $(V)$ was approximately linear and given by the equation $U$

$16=-0.41 \mathrm{~V}$, while this relation was $U=-0.33 \mathrm{~V}$ in juveniles (intercepts ignored). The negative

17 slope confirms this trade-off. As we are forced to treat the effects of variation in expansion

18 volume and expansion time separately when studying the effects of the initial cylinder shape

19 (see below), it's important to realise that the trade-off between suction volume and flow

20 velocity is still inherently present.

\subsection{Snout shape and suction feeding}

23 Whereas that the initial diameter of the snout lies at the heart of a trade-off between expansion

24 volume and flow velocity on one hand and between expansion time and flow velocity on the

25 other hand, our results show that such a trade-off does not exist for snout length. Analysis of 
1 the contour plots suggests that shortening of the snout, while equalizing the work input,

2 increases expansion volume (Fig. 2 A, B) and maximum flow velocity (Fig. 2C, D and Fig.

3 3C) and decreases expansion time (Fig. 3A, B). Furthermore, the pressure gradient (the

4 difference between maximal pressure at the mouth and the pressure just in front of the mouth)

5 also increases with decreasing snout length (Fig. 4). Each of these aspects is related to an

6 increase in suction performance for expansion of shorter snouts. Only in adults, when

7 expansion time is allowed to vary in the CFD simulation, flow velocity appears independent

8 of the length of the expanding snout (Fig. 3D).

9 These findings may explain why long and narrow buccal cavities are not often 10 observed in suction feeding fish. A vast literature on suction feeding in fish exists 11 [e.g., 18,25,37,39,40,41,42,43,44] and most of the fish studied were considered as specialized 12 suction feeding fish. The literature on the buccal shape of suction feeders is limited, however, 13 these studies show that the buccal cavity in rest is relatively wide or deep compared to the 14 buccal cavity length $[18,30,45,46]$. This is in contrast with the buccal cavity shape in 15 syngnathids in which the diameter is relatively small compared to its length [29].

16 There are two possible explanations for the advantages of a long snout related to 17 feeding performance. In the simulations with variable expansion time (Fig. 3), shortening the 18 snout results in higher sub-ambient pressure differences inside the expanding snout (Fig. 3E, 19 F). As we previously argued, it may be preferable for the seahorse to generate suction at the 20 lowest possible intra-oral pressure drops because this ensures minimal stress and strain of the 21 skull [38]. Note, however, that the effect of snout length on intra-oral pressure is slightly 22 different in our set of CFD simulation with variable expansion volume. In the latter case, the 23 effect of sub-ambient pressure differences is independent of snout length (2E, F). An 24 alternative explanation for the existence of a long snout is related to the distinctive feeding 25 strategy of syngnathids, and will be expanded upon below. 
24.2 Snout shape and pivot feeding

3 Syngnathids have a feeding strategy that is different from that of other suction feeding fish,

4 and is typically referred to as pivot feeding [34,35,47]. During pivot feeding, expansion of the

5 buccal cavity is preceded by cranial rotation [29]. In most generalised suction feeders, only

6 the cranium is rotated dorsally while the lower jaw rotates ventrally, which causes an

7 additional volume increase during expansion [25,44]. Syngnathids, on the other hand, rotate

8 the entire head (including upper and lower jaws) to bring the mouth closer to the prey

$9[22,34,35,47]$. Once cranial rotation is near its maximum, the suspensorium starts to abduct

10 [29]. Consequently, snout shape, in pivot feeders, is not only important to generate suction but

11 a lower rotational inertia of the snout will decrease the amount of time needed to bring the

12 mouth close to the prey. For instance, a short snout must achieve a larger rotation than a long

13 snout when the prey is located at an identical position relative to the snout [47]. However,

14 since the total moment of inertia of the head increases with increasing snout length, this

15 negatively affects the angular accelerations during head rotation.

16 A recent model by de Lussanet and Muller [47] predicted the optimal snout length in

17 function of a minimization of the time needed to reach the prey. Interestingly, this model

18 accurately predicts snout lengths of different syngnathid species [47] as well as the snout

19 length of early juveniles in a seahorse species [22]. De Lussanet and Muller [47] use the

20 following formula to calculate reach time:

$$
T \approx \frac{d}{l} \sqrt{\frac{J_{\text {total }}}{2 E}}
$$

22 , in which $d$ is the distance between snout tip and prey, $l$ is the distance between snout tip and 23 centre of rotation, $E$ is the amount of kinetic energy provided by the muscles to rotate the 24 head and $J_{\text {total }}$ is the total moment of inertia relative to the centre of head rotation. The total 25 moment of inertia is the sum of the total moment of inertia of the snout and that of the head 
$1 \quad\left(J_{\text {total }}=J_{\text {head }}+J_{\text {snout }}\right)$, which are represented by an elliptical cylinder and a half-ellipsoid,

2 respectively $[22,47]$. This formula can be applied to our snout shape variations to calculate the

3 minimal reach time of each snout shape. To do so, we calculated the moment of inertia of

4 each snout shape relative to the centre of head rotation (derived from [22]) and recalculated $l$

5 for each snout shape. This means that $d, E, J_{\text {head }}$ and the position of the centre of rotation are

6 equal in each snout shape and based on literature data [22].

7 The shortest minimal reach time is found for a long and slender snout (top left corner,

8 Fig. 5A, B), while the longest minimal reach time is found for a long and broad snout (top

9 right corner, Fig. 5A, B). If pivot feeding only includes a fast rotation of the head towards the prey with no subsequent buccal expansion, the long and slender snout would be most suitable.

11 However, as discussed previously, a long snout has the lowest suction performance.

12 Obviously for a long and slender snout, it is of no use to reach the prey extremely fast, if

13 followed by a small volume increase and accompanied by a relatively low flow velocity (see

14 Fig. 2 top left corners of the panels) or followed by a very long expansion time during which

15 no significantly higher flow velocity is generated (see Fig. 3 top left corners of the panels).

16 For example, doubling the length of the snout of our seahorses implies an increase in minimal

17 reach time by at least $10 \%$ in juveniles and $20 \%$ in adults (Fig. 4A, B), which can be critical

18 for capturing prey.

Apparently, pivot feeders are challenged by an important trade-off between head 20 rotation and snout expansion. Longer and narrower snouts have the highest performance with 21 respect to cranial rotation (performance defined as the ability to minimize prey reach time), 22 but the lowest in some aspects of suction performance. Shorter snouts have a higher suction 23 performance, but the performance of cranial rotation decreases. Perhaps the observed snout 24 shape in animals like Hippocampus reidi is simply the best compromise between performance 25 of cranial rotation and suction feeding. 
24.3 Ontogeny of snout shape and pivot feeding

3 Despite that this study suggests that the observed snout shape in Hippocampus reidi is a

4 compromise between different aspects of feeding performance for both juveniles as well as

5 adults, it is remarkable that such a pronounced snout allometry exists during ontogeny

$6 \quad[22,24]$. The snout grows from a relatively short and broad snout, as observed in juveniles, to

7 a relatively more slender and long snout. Undoubtedly this snout allometry affects suction

8 feeding and cranial rotation performance. As suggested by a previous study [22], the

9 measured snout in early juveniles is slightly shorter than the optimal snout length predicted by

10 the model of de Lussanet and Muller [47], which means that the minimal time to reach the

11 prey of the measured snout length is higher than that of the calculated optimal snout length

12 [22]. However, this difference in minimal reach time is less than $1 \%$ indicating that the

13 deviation from the optimal solution is relatively small. The consequences for suction feeding

14 of this small deviation of snout length from the optimum for cranial rotation is illustrated by

15 the grey circles in Figures 2 and 3: our model predicts a slight increase in suction velocity

$16(<10 \%)$, an increase in the maximally realizable volume increase $(+15 \%)$ and a decrease in

17 the time needed to expand the snout (-15\%). In adults, on the other hand, the optimal snout

18 length and the measured snout length showed no differences [22].

The results of the present study indicate that the trade-off between suction

20 performance and cranial rotation performance is relatively in favour of suction feeding in

21 early juveniles, and becomes more in favour of cranial rotation when the adult snout shape is

22 reached. Scaling of the juvenile snout to the volume of the adult snout (snout volume of

23 juveniles of 1,2 and 3 weeks are added based on the study by Roos and colleagues [22])

24 shows how the observed snout allometry affects suction feeding and cranial elevation

25 (indicated by the arrow in Fig. 2, 3, 4 and 5). In the first set of simulations (work input and 
1 expansion time are constant, Fig. 2), the existing snout allometry causes a negative effect on

2 expansion volume and maximal pressure, since they both increase, and has a positive effect

3 on maximal flow velocity. In the second set of simulations (work input and expansion volume

4 are constant, Fig. 3), snout allometry negatively affects expansion time and maximal flow

5 velocity, but positively affects the intra-oral pressure drop which needs to be sustained by the

6 suspensorial bones. In addition, the existing snout allometry has a positive effect on minimal

7 reach time, since the latter decreases during ontogeny (Fig. 5). These findings suggest that

8 snout allometry influences suction performance negatively, but cranial rotation performances

9 positively. In general, newborn juveniles are capable of engulfing relatively larger volumes of

10 water and expanding their snout in less time compared to adults, which indicates a higher

11 suction performance. Kinematic data confirm these model predictions by showing a faster and

12 relatively larger expansion in juvenile Hippocampus reidi [20]. In turn, adults are able to

13 reach their prey faster compared to juveniles, indicating a higher cranial rotation performance.

14 This observed morphology in juveniles optimised towards suction feeding may be the result

15 of their small absolute size favouring a relatively large and fast expansion to maximise the

16 potential prey spectrum. For adults, prey size is likely less of a constraint and faster head

17 rotation velocities may allow them to use more dedicated ambush style foraging tactics while

18 remaining cryptic for predators.

\subsection{Conclusion}

21 This study addressed the question whether the observed snout allometry during ontogeny in 22 the seahorse Hippocampus reidi can be explained by hydrodynamic constraints. To answer 23 this question we formulated two hypothesises: (1) the juveniles expelled from the male's 24 brood pouch have a snout that is suboptimal for suction feeding. Therefore, the snout 25 proportions change rapidly to bypass the suboptimal stage as quickly as possible. (2) The 
1 snout dimensions in newborn juveniles are already optimised for suction feeding and the

2 snout allometry is dictated by the changing hydrodynamic constraints during growth (for

3 example the gradually less viscous flow regime). Surprisingly, our results indicate that both

4 hypothesises must be rejected since a relatively shorter snout than the snout measured in

5 juveniles is predicted to have a have higher suction performance (contra hypothesis 1), while

6 the snout grows in the opposite direction from moving forwards this optimum to become

7 relatively longer in adults (contra hypothesis 2 ). We argued that snout length in syngnathids

8 H. reidi, in contrast to more typical suction feeders, is constrained by its performance in the

9 quick rotation of the head to bring the mouth close to the prey, which precedes expansion of

10 the snout to generate suction in these fish. Consequently, our study highlights a trade-off

11 between cranial rotation and suction feeding. As the seahorses grow, the observed relative

12 decrease in snout diameter improves the time to reach the prey, but on the other hand this

13 decrease in snout diameter will negatively affect suction performance.

\section{Acknowledgements}

17 G.R. is funded by a PhD grant of the Institute for the Promotion of Innovation through 18 Science and Technology in Flanders (IWT-Vlaanderen). S.V.W. is postdoctoral fellow of the 19 Fund for Scientific Research, Flanders (FWO-V1). Supported by FWO-V1 grant G 053907.

\section{$21 \quad$ Literature cited}

23 [1] S.M. Reilly, The ontogeny of aquatic feeding behaviour in Salamandra salamandra: 24 stereotypy and isometry in feeding kinematics, J. Exp. Biol. 198 (1995) 701-708. 
1 [2] B.A. Richard, P.C. Wainwright, Scaling of the feeding mechanism of largemouth bass

2 (Micropterus salmoides): kinematics of prey capture, J. Exp. Biol. 198 (1995) 419-433.

3

4 [3] D.R. Carrier, Ontogenetic limits on locomotor performance, Physiol. Zool. 69 (1996) 4675488.

6

7 [4] J.J Meyers, A. Herrel, J. Birch, Scaling of morphology, bite force and feeding kinematics 8 in an iguanian and a scleroglossan lizard, in: P. Aerts, K. D’Aout, A. Herrel, R. Van Damme 9 (Eds.), Topics in Functional and Ecological Vertebrate Morphology. Shaker, Maastricht, 10 Netherlands, 2002, pp. 47-62.

[5] S. Vincent, A. Herrel, D.J. Irschick, Ontogeny of intersexual head shape and prey selection in the pitviper Agkistrodon piscivorus, Biol. J. Linn. Soc. 81 (2004) 151-159.

14

[6] D. Adriaens, P. Aerts, W. Verraes, Ontogenetic shift in mouth opening mechanisms in a catfish (Clariidae, Siluriformes): A response to increasing functional demands, J. Morphol. 247 (2001) 197-216.

[7] I. Hunt von Herbing, Development of feeding structures in larval fish with different life histories: winter flounder and Atlantic cod, J. Fish Biol. 59 (2001) 767-782.

[8] P.M. Larson, Ontogeny, phylogeny, and morphology in anuran larvae: A morphometric analysis of cranial development and evolution in Rana larvae (Anura: Ranidae), J. Morphol. 264 (2005) 34-52. 
1 [9] K. Schmidt-Nielsen, Scaling: Why Is Animal Size So Important? Cambridge University

2 Press, Cambridge, 1984.

3

4 [10] A. Herrel, A.C. Gibb, Ontogeny of performance in vertebrates, Physiol. Biochem. Zool. $579(2006) 1-6$.

6

7 [11] L.P. Hernandez, P.J. Motta, Trophic consequences of differential performance: ontogeny 8 of oral jaw crushing performance in the sheepshead, Archosargus probatocephalus (Teleostei:

9 Sparidae), J. Zool. (Lond.) 243 (1997) 737-756.

[12] A. Herrel, J.C. O’Reilly, Ontogenetic scaling of bite force in lizards and turtles, Physiol.

12 Biochem. Zool. 79 (2006) 31-42.

14 [13] G.M. Erickson, A.K. Lappin, K.A. Van Vliet, The ontogeny of bite-force performance in 15 American alligator (Alligator mississipiensis), J. Zool. (Lond.) 260 (2003) 317-327.

17 [14] A. Herrel, J. Podos, S.K. Huber, A.P. Hendry, Bite performance and morphology in a population of Darwin's finches: implications for the evolution of beak shape, Funct. Ecol. 19 (2005) $43-48$.

[15] W.J. Binder, B.J. Van Valkenburgh, Development of bite strength and feeding behaviour in juvenile spotted hyenas (Crocuta crocuta). J. Zool. (Lond.) 252 (2000) 273-283.

24 [16] L.P. Hernandez, Intraspecific scaling of feeding mechanics in an ontogenetic series of 25 zebrafish, Danio rerio, J. Exp. Biol. 203 (2000) 3033-3043. 
2 [17] M.P. Robinson, P.J. Motta, Patterns of growth and the effects of scale on the feeding

3 kinematics of the nurse shark (Ginglymostoma cirratum), J. Zool. (Lond.) 256 (2002) 449-

4462.

5

6 [18] S. Van Wassenbergh, P. Aerts, A. Herrel, Hydrodynamic modelling of aquatic suction

7 performance and intra-oral pressures: limitations for comparative studies, J. R. Soc. Interface $83(2006) 507-514$.

9

10

[19] R. Holzman, D.C. Collar, S.W. Day, K.L. Bishop, P.C. Wainwright, Scaling of suction-

11 induced flows in bluegill: morphological and kinematic predictors for the ontogeny of feeding 12 performance, J. Exp. Biol. 211 (2008) 2658-2668.

14 [20] S. Van Wassenbergh, G. Roos, A. Genbrugge, H. Leysen, P. Aerts, D. Adriaens, A. 15 Herrel, Suction is kid's play: extremely fast suction in newborn seahorses, Biol. Lett. 5 (2009) $16 \quad 200-203$.

17

[21] H. Leysen, P. Jouk, M. Brunain, J. Christiaens, D. Adriaens, Cranial architecture of tubesnouted gasterosteiformes (Syngnathus rostellatus and Hippocampus capensis), J. Morph. 271 (2010) 255-270.

[22] G. Roos, S. Van Wassenbergh, A. Herrel, D. Adriaens, P. Aerts, Snout allometry in 23 seahorses: insights on optimisation of pivot feeding performance during ontogeny, J. Exp. Biol. (in press). 
1 [23] E.S. Kornienko, Reproduction and development in some genera of pipefish and

2 seahorses of the family Syngnathidae, Russ. J. Mar. Biol. 27 (2001) S15-S26.

3

4 [24] C.K. Choo, H.C. Liew, Morphological development and allometric growth patterns in the 5 juvenile seahorse Hippocampus kuda Bleeker, J. Fish Biol. 69 (2006) 426-445.

7 [25] G.V. Lauder, Aquatic feeding in lower vertebrates, in: M. Hildebrand, D.M. Bramble, 8 K.F. Liem, D.B. Wake (Eds.), Functional vertebrate morphology, The Belknap Press 9 (Harvard University Press), Cambridge, 1985, pp. 210-229.

[26] P.C. Wainwright, S.W. Day, The forces exerted by aquatic suction feeders on their prey,

J. R. Soc. Interface 4 (2007) 533-560.

[27] M.R. Drost, M. Muller, J.W.M. and Osse, A quantitative hydrodynamic model of suction feeding in larval fishes: the role of frictional forces, Proc. R. Soc. B 234 (1988) 263-281.

[28] S. Van Wassenbergh, P. Aerts, Aquatic suction feeding dynamics: insights from computational modelling J. R. Soc. Interface 6 (2009) 149-158.

[29] G. Roos, S. Van Wassenbergh, A. Herrel, P. Aerts, Kinematics of suction feeding in the seahorse Hippocampus reidi, J. Exp. Biol. 212 (2009) 3490-3498. suction feeding in fish, J. Theor. Biol. 95 (1982) $49-79$. 
1 [31] A.M. Carroll, P.C. Wainwright, S.H. Huskey, D.C. Collar, R.G. Turingan, Morphology

2 predicts suction feeding performance in centrarchid fishes, J. Exp. Biol. 207 (2004) 3873-

33881.

4

5 [32] A.M. Carroll, P.C. Wainwright, Muscle function and power output during suction

6 feeding in largemouth bass, Micropterus salmoides, Comp. Biochem. Physiol. 143 (2006)

$7 \quad 389-399$.

8

9 [33] D.J. Coughlin, A.M. Carroll, In vitro estimates of power output by epaxial muscle during

10 feeding in largemouth bass, Comp. Biochem. Physiol. 145 (2006) 533-539.

11

12 [34] S. Van Wassenbergh, J.A. Strother, B.E. Flammang, L.A. Ferry-Graham, P. Aerts, 13 Extremely fast prey capture in pipefish is powered by elastic recoil, J. R. Soc. Interface 5 14 (2008) 285-296.

15

16 [35] M. Muller, Optimization principles applied to the mechanism of neurocranium levation 17 and mouth bottom depression in bony fishes (Halecostomi), J. Theor. Biol. 126 (1987) 34318368.

19

20 [36] T.E. Higham, S.W Day, P.C Wainwright, Multidimensional analysis of suction feeding 21 performance in fishes: fluid speed, acceleration, strike accuracy and the ingested volume of 22 water, J. Exp. Biol. 209 (2006) 2713-2725.

23

24 [37] R. Holzman, S.W Day, R.S. Mehta, P.C. Wainwright, Integrating the determinants of 25 suction feeding performance in centrarchid fishes, J. Exp. Biol. 211 (2008) 3296-3305. 
2 [38] M.J. Markey, R.P. Main, C.R. Marshall, In vivo cranial suture function and suture

3 morphology in the extant fish Polypterus: implications for inferring skull function in living

4 and fossil fish, J. Exp. Biol. 209 (2006) 2085-2102.

5

6 [39] K.F. Liem, Modulatory multiplicity in the functional repertoire of the feeding mechanism 7 in cichlid fishes. I. Piscivores, J. Morphol. 158 (1978) 323-360.

9 [40] J.L. Van Leeuwen, M. Muller, Optimum sucking techniques for predatory fish. Trans. 10 Zool. Soc. Lond. 37 (1984) 137-169.

11

12 [41] P.C. Wainwright, G.V. Lauder, Feeding biology of sunfishes: patterns of variation in 13 prey capture, Zool. J. Linn. Soc. Lond. 88 (1986) 217-228.

14

15 [42] A.C. Gibb, Do flatfish feed like other fishes? A comparative study of percomorph prey 16 capture kinematics, J. Exp. Biol. 200 (1997) 2841-2859.

17

18 [43] R. Svanbäck, P.C. Wainwright, L.A. Ferry-Graham, Linking cranial kinematics, buccal 19 pressure, and suction feeding performance in largemouth bass, Physiol. Biochem. Zool. 75 $20 \quad$ (2002) 532-543.

21

22 [44] A.C. Gibb, L.A. Ferry-Graham, Cranial movements during suction feeding in teleost 23 fishes: are they modified to enhance suction production? Zoology 108 (2005) 141-153. 
1 [45] C.D.N. Barel, Towards a constructional morphology of cichlid fishes (Teleostei,

2 Perciformes), Neth. J. Zool. 4 (1983) 357-424.

3

4 [46] S. Van Wassenbergh, T. Lieben, A. Herrel, F. Huysentruyt, T. Geerinckx, D. Adriaens,

5 P. Aerts, Kinematics of benthic suction feeding in Callichthyidae and Mochokidae, with

6 functional implications for the evolution of food scraping in catfishes, J. Exp. Biol. 212 $7 \quad$ (2009) 116-125.

9 [47] M.H.E. de Lussanet, M. Muller, The smaller your mouth, the longer your snout: predicting the snout length of Syngnathus acus, Centriscus scutatus and other pipette feeders,

11 J. R. Soc. Interface 4 (2007) 561-573.

Figure legends

14

15 Fig. 1: Illustration of the 2D axisymmetric, triangular mesh used in the simulations (A). Snout height, width and length were used as input to set the initial dimensions of the cylindrical

17 snout model. This mesh was imported into FLUENT in which radial abduction of the snout was simulated (C). Note that the average measured adult snout was used in the representative figures. Similar methods were used to model juvenile snout expansion.

21 Fig. 2: The results of the CFD simulations in which the work input and the expansion time were unchanged for different snout shapes. The values of realised volume expansion (A, B),

23 flow velocity at the mouth aperture $(\mathrm{C}, \mathrm{D})$ and sub-ambient pressure magnitude $(\mathrm{E}, \mathrm{F})$ are 24 shown as proportions relative to the model output of the average measured snout shape (black 25 circle) for juveniles (A, C, E) and adults (B, D, F). In the juvenile column the snout length 
1 optimised for head rotation (based on data of Roos and colleagues [22]) predicted by the

2 model of de Lussanet and Muller [47] was marked as a grey point (for details see text). In the

3 adult column, the grey line represents the growth line of the snout shape from a juvenile of

4 less than one week old to the adult snout shape (snout shape was isometrically scaled to the

5 adult buccal volume).

7 Fig. 3: The results of the CFD simulations in which the work input and the expansion volume 8 were unchanged for different snout shapes. The values of expansion time $(A, B)$, flow

9 velocity at the mouth aperture (C, D) and sub-ambient pressure magnitude (E, F) are shown as 10 proportions relative to the model output of the average measured snout shape (black circle) 11 for juveniles (A, C, E) and adults (B, D, F). In the juvenile column the snout length optimised 12 for head rotation (based on data from Roos and colleagues [22]) predicted by the model of de 13 Lussanet and Muller [47] was marked as a grey point (for details see text). In the adult 14 column, the grey line represents the ontogenetic line of the snout shape from a juvenile of less 15 than one week old to the adult snout shape (snouts isometrically scaled to match the adult 16 buccal volume).

18 Fig. 4: The results of the pressure gradient for each different juvenile (left column) and adult 19 (right column) snout shape. All values are represented as proportions relative to the model 20 output of the average measured snout (black circle). In the juvenile column the snout length 21 optimised for head rotation (based on data from Roos and colleagues [22]) predicted by the 22 model of de Lussanet and Muller [47] was marked as a grey point (for details see text). In the 23 adult column, the grey line represents the ontogenetic line of the snout shape from a juvenile 24 of less than one week old to the adult snout shape (snouts isometrically scaled to match the 25 adult buccal volume). 
2 Fig. 5: The results of the minimal reach time (time to reach the prey with the mouth by cranial 3 rotation) for each snout shape obtained by applying the model presented by de Lussanet and

4 Muller [47]. The values are shown as proportions relative to the average measured snout 5 shape (filled circle) for juveniles (left column) and adults (right column). In the juvenile 6 column the optimal snout length (based on data from Roos and colleagues [22]) predicted by

7 the model was marked as a grey point (for details see text). In the adult column, the grey line

8 represents the ontogenetic line of the snout shape from a juvenile of less than one week old to 9 the adult snout shape (snouts isometrically scaled to match the adult buccal volume). 
A neight

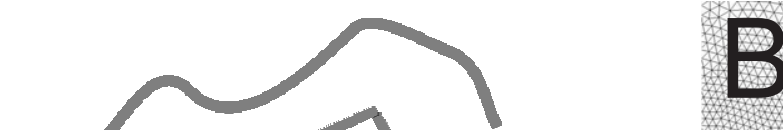

Iwidth :

B
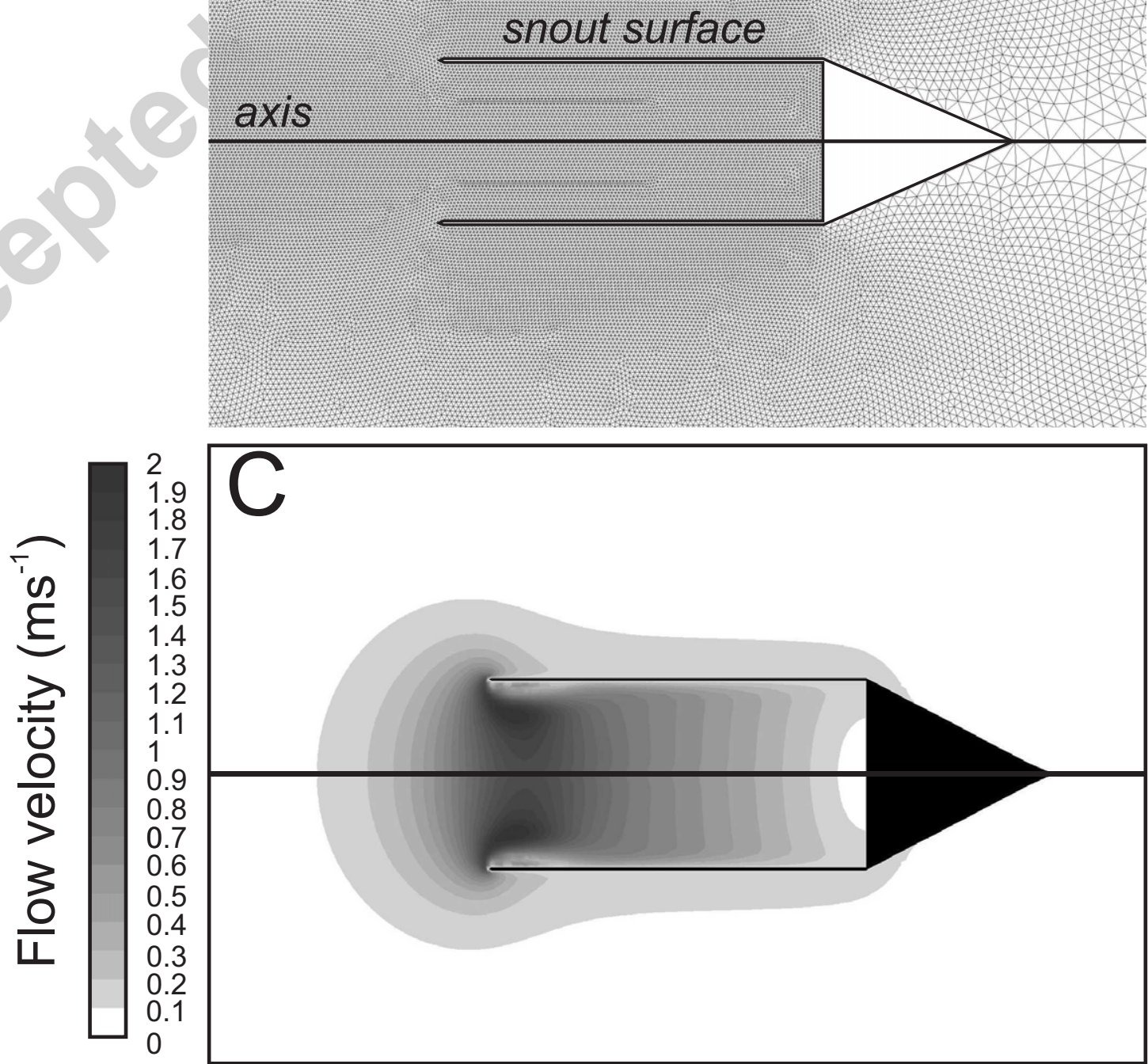

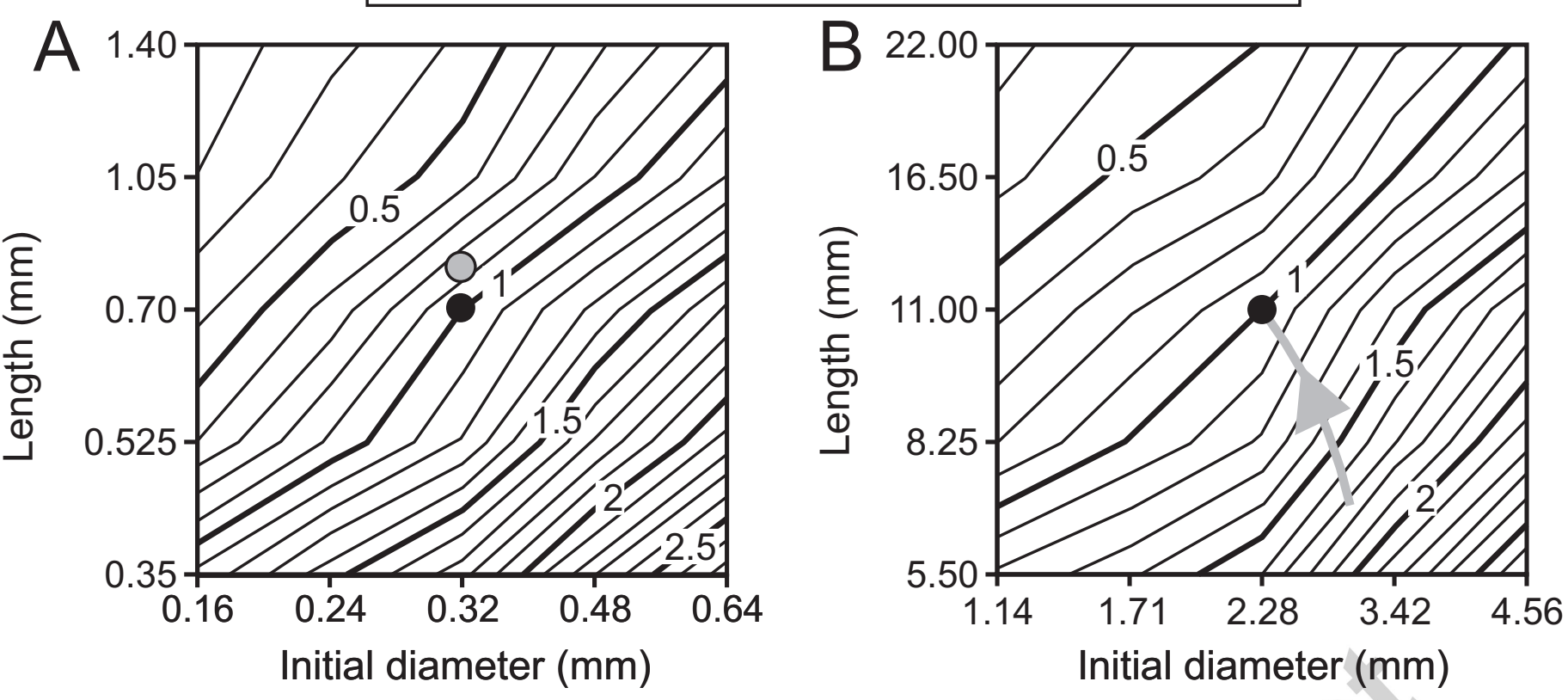

C
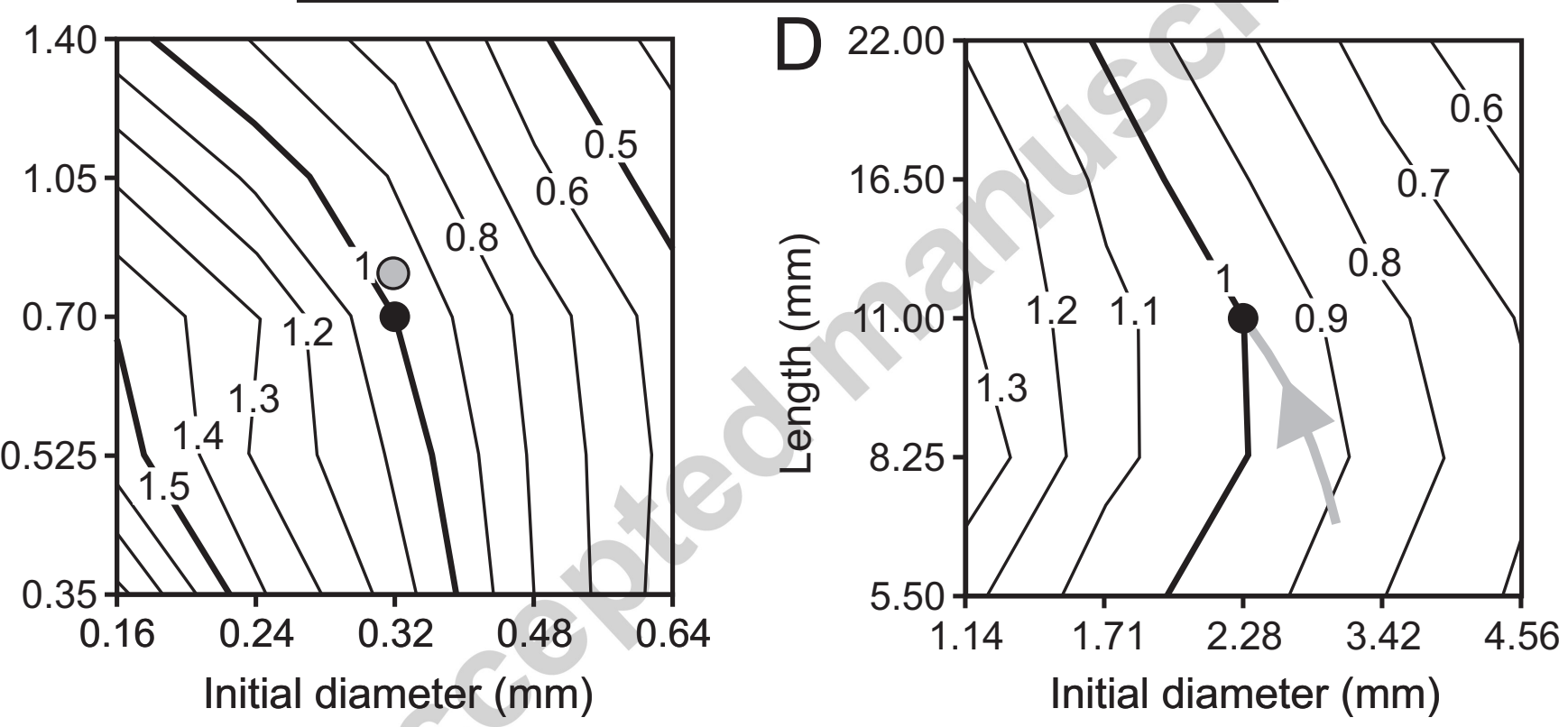

Iso-sub-ambient pressure magnitude curves

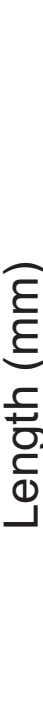

$E$
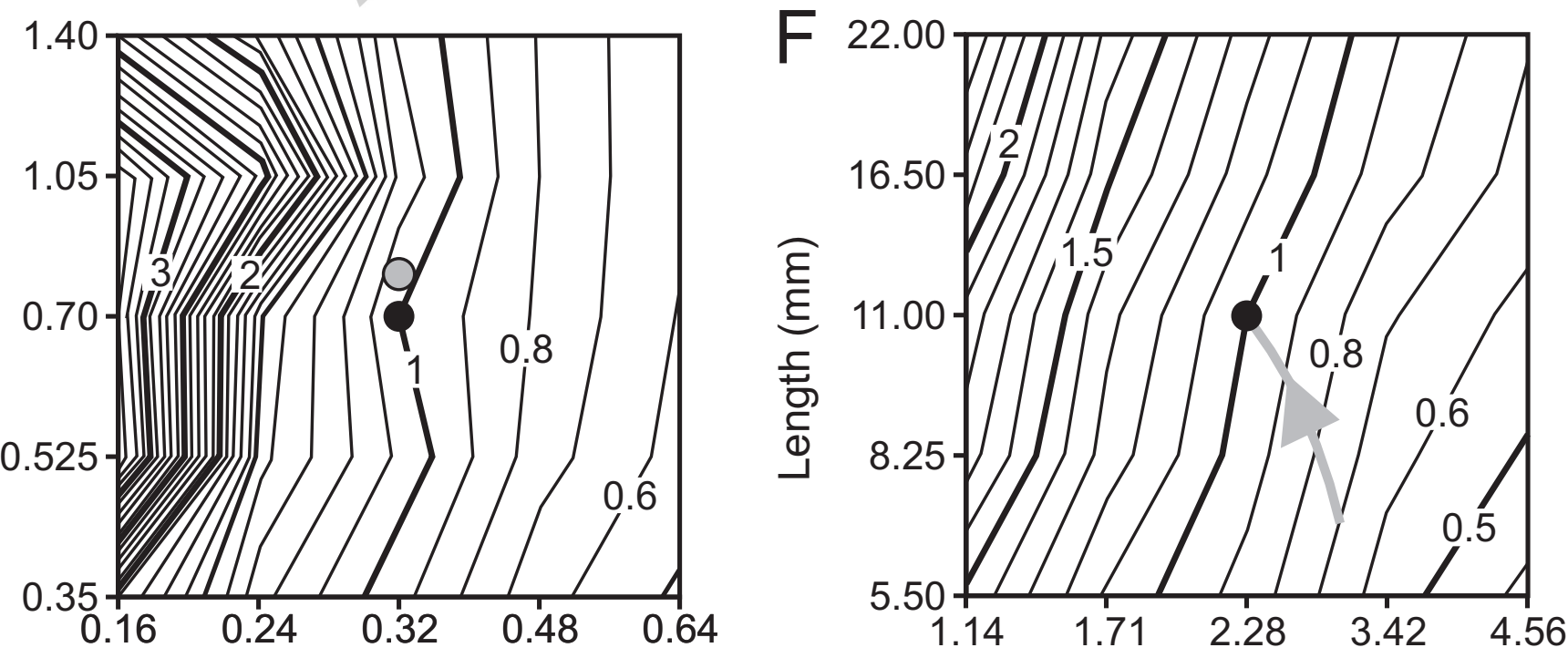

Initial diameter (mm)

Initial diameter (mm) 


\section{Iso-minimal reach time curves}

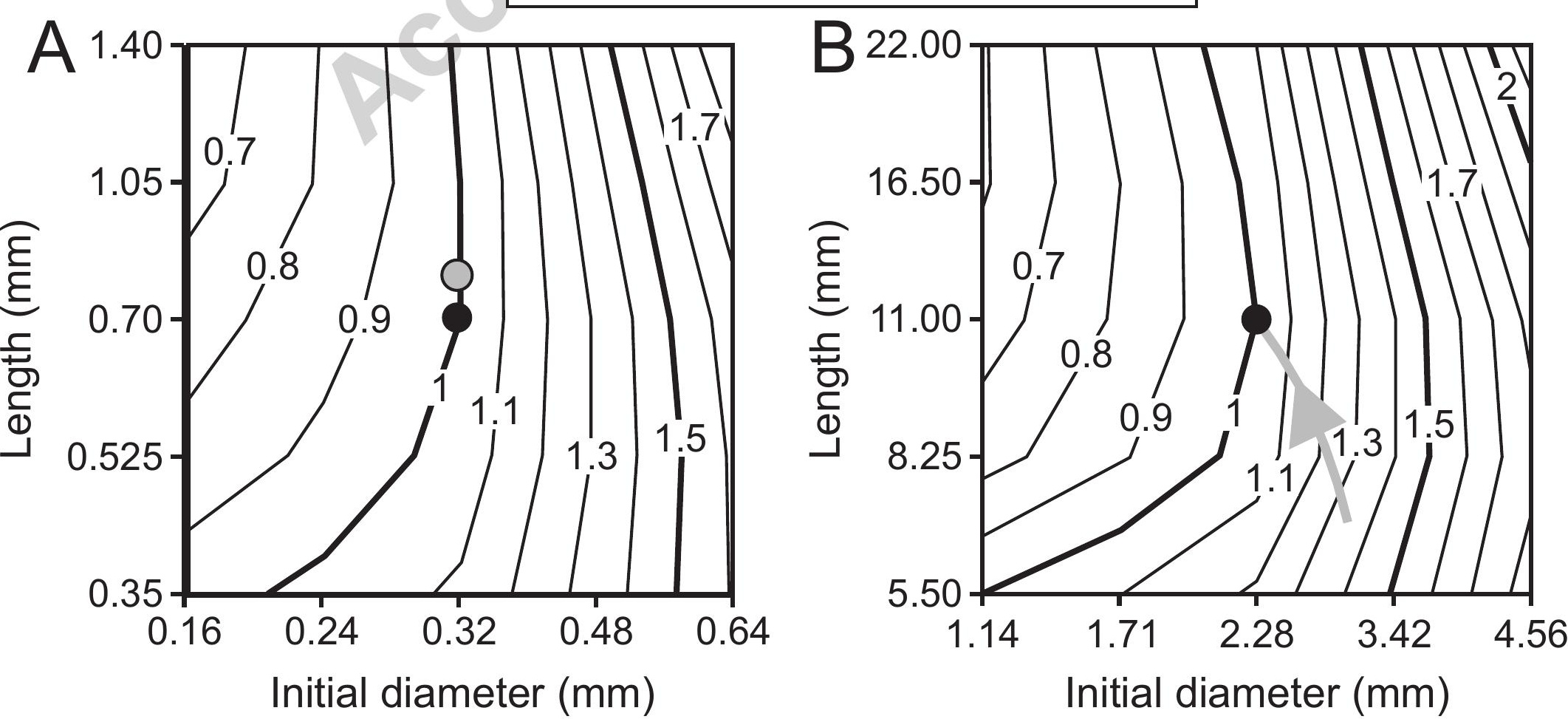

